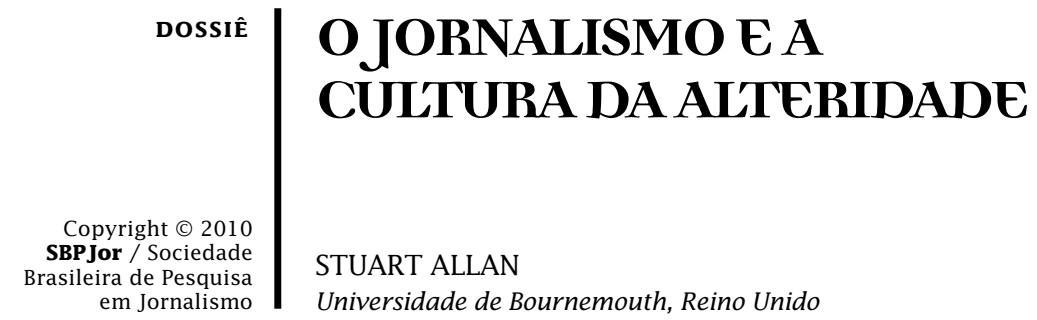

RESUMO Ao procurar tornar problemáticas as concepções tradicionais da identidade jornalística, este artigo oferece uma crítica às estruturas aparentemente naturais, "de bom senso", sobre a exclusão social, que atualmente sustentam a sua formulação. Em primeiro lugar, e, mais especificamente, explora uma série de insights fornecidos por feministas e por perspectivas críticas de tratamento de gêneros no jornalismo. Ao avaliar os imperativos tipicamente sutis do sexismo na reportagem das notícias, ele sugere, na medida em que a identidade jornalística continua a ser definida pela "cultura machista" no cotidiano da redação, onde as percepções da discriminação sexual das jornalistas do sexo feminino costumam variar acentuadamente em relação às de seus colegas do sexo masculino. Em segundo lugar, o texto foca a questão da diversidade étnica, onde a necessidade de desconstruir a projeção racista das dicotomias "nós e eles", exatamente como assumidas e refletidas na reportagem das notícias, se revela como uma preocupação urgente. Ao juntar estes respectivos conjuntos de debates, principalmente de contextos britânicos e norte-americanos, este artigo visa contribuir com esforços conceituais para esclarecer ainda mais as maneiras pelas quais as escolhas rotineiras e cotidianas dos jornalistas com relação àquilo que é para relatar - qual a melhor maneira de fazê-lo, e por que - os envolvem numa política de mediação, na qual uma cultura de alteridade se mostra muitas vezes significativa.

Palavras-chave: Jornalismo. Identidade. Profissionalismo. Sexismo. Racismo. Alteridade.

\title{
INTRODUÇ̃̃O
}

Numa carta para um dos seus redatores, o proprietário de jornais norte-americanos Joseph Pulitzer - famoso hoje pelos prêmios concedidos pela excelência no jornalismo e que levam seu nome ofereceu seus pensamentos sobre como assegurar a melhor maneira do jornal servir sua comunidade de leitores. Um trecho que vale destacar especialmente dizia:

Cada edição do jornal apresenta uma oportunidade e um dever de dizer algo corajoso e verdadeiro, de passar por cima do medíocre e 
do convencional, de dizer algo que vai merecer o respeito da parte inteligente, instruída e independente da comunidade, de passar por cima do medo do partidarismo e do medo do preconceito popular (apud SEITZ, 1924, p. 286; ver também IRELAND, 1938).

A carta, enviada a George S. Johns do Post-Dispatch no dia 10 de agosto de 1906, evocou um ideal de serviço público em termos elegantes. Por ocasião da morte de Pulitzer em outubro de 1911, esta visão - juntamente com opiniões sobre a relativa extensão do que foi realizado - constou em diversas avaliações do trabalho da vide dele, bem como do impacto dos seus jornais na formação do "novo jornalismo" da época. Em setembro do ano seguinte, graças à sua generosidade (isto é, uma doação de 2 milhões de dólares), a primeira turma de alunos chegou para assistir ao seu primeiro dia de aulas na Escola de Jornalismo na Universidade de Columbia em Nova Iorque (BOYLAN, 2003). A motivação de Pulitzer de ajudar a arcar com os custos do novo programa se baseava diretamente no seu desejo de assegurar a base de uma concepção radicalmente diferente da identidade profissional a ser sustentada. Em jogo, na opinião dele, estava nada menos que o próprio futuro da vida democrática.

Contrastando com as profissões de direito ou de medicina, que adotaram procedimentos rígidos para a entrada, códigos autorizados de ética e métodos formais de autorregulação, nenhuma das tais medida foi considerada consistente com a prática do jornalismo prevista para os futuros formados pela Columbia. Certamente era a crença firme de Pulitzer (1904), entretanto, que o status do jornalismo - ou seja, sua elevação tanto aos olhos dos leitores quanto para os próprios jornalistas - merecesse, contudo, o igual reconhecimento. O profissionalismo, em todos os sentidos do termo, forneceria os valores orientadores aos quais todos os jornalistas deveriam aspirar. Os fatores que configurariam a formação da identidade girariam em torno de um compromisso declarado com as virtudes do espírito público. Exatamente o que o concomitante "padrão da justiça cívica" imaginado por Pulitzer englobaria desafiou uma elucidação fácil, encontrando ao invés disso apenas uma definição ampla com relação ao "caráter" necessário para promover o "bem-estar público". A coragem moral, tão vital para o serviço público, teria que ser ensinada - uma aptidão, em acordo com os seus princípios, e com ela a determinação de se comportar de forma responsável não era inata. É aqui que a distinção feita por Pulitzer entre "os verdadeiros jornalistas" e "os homens [e as mulheres] que fazem um tipo de trabalho no jornal que não exige nem o conhecimento nem a convicção" sublinhou a diferença 
entre as qualidades pessoais a serem engendradas pela educação jornalística e aquelas derivadas "apenas do treinamento empresarial" (PULITZER, 1904, p. 19). Ser culto, de qualquer maneira, era um "orgulho da profissão", porque somente o jornalista "tem o privilégio de moldar a opinião, tocar os corações e apelar para a razão de centenas de milhares todos os dias". Todos os dias, acrescentou, "abrem portas novas para o jornalista que tem a confiança da comunidade e tem a capacidade de dirigir-lhes a palavra" (Ibid, p. 12).

Visto da perspectiva atual, a avaliação corajosa feita por Pulitzer dos critérios normativos, que dão forma à sua configuração preferida da identidade jornalística, ajuda a iluminar algumas das premissas dadas por certas que contribuem para as percepções atuais dos jornalistas referentes ao seu papel. Existe uma determinada mitologia que enfatiza esta aspiração aos ideais democráticos (variando desde as reivindicações feitas por organizações que os defendem aos retratos ficcionais do jornalismo na mídia de entretenimento, e mais além), apesar do ceticismo recorrente expressado pelos próprios jornalistas, que envolve tais "visões" do seu ofício (ALLAN, 2010a, 2010b; no contexto brasileiro, ver DE ALBUQUERQUE, 2005; HERSCOVITZ, 2004; MARQUES DE MELO, 2009; MARTINEZ, 2008). É mais frequente, entretanto, que estes discursos conhecidos de identidade, quando lidos de maneira contrária à sua aparência, revelem sua dependência das estruturas normalizadas de exclusão social que merecem uma análise cuidadosa.

Assim, ao procurar identificar e criticar estas estruturas aparentemente normais, até de bom senso, este artigo vai explorar, primeiro, uma série de percepções fornecidas pelas críticas feministas do jornalismo e sensíveis ao gênero. Ao avaliar os imperativos tipicamente sutis do sexismo na reportagem de notícias, será demonstrado que percepções importantes poderão ser obtidas da dinâmica do gênero do que se descreve frequentemente como "cultura machista" nas redações. Em segundo lugar, a atenção vira para a questão da diversidade étnica, onde a necessidade de desconstruir a projeção racista das dicotomias "nós e eles" exatamente como assumidas e refletidas na reportagem das notícias se revela como uma preocupação urgente. Ao juntar estes conjuntos de debates respectivos, principalmente, aos contextos britânicos e norte-americanos, este artigo visa contribuir com os esforços conceituais para desemaranhar ainda mais as maneiras pelas quais as escolhas rotineiras e cotidianas dos jornalistas, com relação àquilo que é para relatar - qual a melhor maneira de fazê-lo, e por que - envolvem os jornalistas numa política de mediação, na qual uma cultura de alteridade 
se mostra muitas vezes significativa.

\section{O sexismo e o jornalismo}

Diversos relatos históricos sugerem que o problema do sexismo poderá ser percebido desde os primórdios do jornalismo, o que é pouco surpreendente (CHAMBERS, STEINER e FLEMING, 2004). No entanto, dirijase para um cenário mais recente, em Washington, D.C. em janeiro de 2007, quando funcionários da Casa Branca convidaram âncoras das redes e TV a cabo, além de anfitriões dos shows políticos de domingo, para uma reunião com altos membros da administração Bush para discutir a guerra do Iraque. Mais tarde, Katie Courie (2007) da CBS News se lembrou da sensação da reunião ter sido "um tanto desconcertante" quando, olhando ao redor da sala, se deu conta de que alguma coisa estava errada.

\footnotetext{
Não pude deixar de observar, apesar de termos ido tão longe, que eu era a única mulher lá. Bem, havia algumas funcionárias de apoio perto da porta. Mas de todas as pessoas à mesa, os "principais" na reunião, eu era a única usando saia. Todo o mundo foi afável, embora a atmosfera jocosa fosse palpável.

O movimento feminista que começou nos anos 1970 ajudou as mulheres a fazerem um progresso tremendo - mas ainda não tem havido um número suficiente de grandes saltos para a mulher. [...] Aquela reunião foi uma verificação da realidade para mim - e não apenas sobre o Iraque. Foi um lembrete de que todos nós temos uma obrigação de perguntar: mais mulheres não merecem um lugar na mesa também? (COURIE, 2007).
}

Atualmente a cultura cotidiana de notícias da maioria dos jornais e das organizações de difusão ainda está sendo definida em termos predominantemente masculinos. Embora tenha havido um aumento dramático no número de mulheres que conseguem empregos no jornalismo, os homens brancos da classe média continuam ocupando a grande maioria das posições de poder no setor inteiro. As mulheres ainda não estão sendo promovidas aos altos postos com poder decisório na proporção do papel global que elas despenham na profissão. Numa época em que as organizações noticiosas enfrentam formas cada vez mais intensivas (e cada vez mais globalizadas) de concorrência, os custos desta falha de não tratar as mulheres de uma maneira justa no lugar de trabalho jornalístico continuam aumentando.

Diversas pesquisadoras defendem que, embora o êxito das jornalistas femininas com alto perfil - tais como a Courie, mencionada acima - tenha avançado uma distância considerável na direção de derrubar as barreiras à igualdade dos gêneros, apesar disso, estas permanecem teimosamente intactas (CARTER, BRANSTON e ALLAN, 1998; CHAMBERS, STEINER e FLEMING, 2004; DE BRUIN e ROSS, 2004; 
EVERBACH, 2006; NORTH, 2009). Um levantamento recente conduzido pela American Society of Newspaper Editors (Sociedade Americana de Redatores de Jornais - ASNE), por exemplo, concluiu que os homens continuam excedendo em número as mulheres nas posições de tempo integral nos jornais diários com uma margem de 63 por cento contra 37 por cento (ASNE, 2008). O mesmo estudo descobriu que as mulheres de minorias representam 17 por cento do quadro de pessoal feminino nas redações, revelando assim uma dimensão ainda maior das desigualdades institucionalizadas. Os estudos das organizações de notícias britânicas mostram, consistentemente, que a grande maioria dos jornalistas sêniors e dos redatores com poder decisório são homens, sendo que a maioria das estimativas revela um número acima de 80 por cento. A pesquisa recente conduzida pela Sutton Trust (2006), por exemplo, indica que "a proporção de mulheres entre os mais importantes jornalistas de notícias aumentou de 10 por cento em 1986 para 18 por cento em 2006" (ver também CHRISTMAS 1997; WOMEN IN JOURNALISM 1998). "Os homens brancos da classe média têm pintado e bordado na BBC desde a época do Lord Reith e é francamente incrível que ainda estejam pintando e bordando no novo milênio", afirmou recentemente a ex-locutora de notícias da BBC, Anna Ford, (apud WALKER, 2008). A jornalista Glender Cooper (2008) reafirma esta visão referente à sua própria experiência. Quando ela entrou na BBC em 2002, lembra, "Fui levada ao lado de um redator (outro homem branco da classe média, tão adaptado ao sistema que foi promovido logo depois) que me deu conselhos sobre como conseguir ser uma jornalista de notícias séria". Ela acrescenta que ele sugeriu "que alisasse meu cabelo naturalmente crespo para aparecer mais 'confiável'. Ele também lamentou que os meus olhos parecessem grandes demais na tela" (COOPER, 2008).

Os fatores envolvidos são complexos, como Aldridge (2001) indica com base no seu estudo envolvendo entrevistas com mulheres que trabalham na imprensa regional do Reino Unido, mas parece que têm a ver com as hierarquias de status baseadas na experiência com as "notícias sérias". O que poderão parecer crenças arraigadas numa meritocracia baseada no desempenho, conforme sugerem os resultados do seu estudo, seriam explicadas melhor em termos de barreiras estruturais ao avanço:

Nos jornais, afirma-se constantemente, você é apenas tão bom quanto o seu trabalho mais recente, no entanto esta lógica de desempenho não é observada na prática. Para chegar a uma posição de influência, você não apenas precisa demonstrar aptidões $e$ habilidades correntes, mas também experiência 
específica no passado, crucialmente num posto sênior relacionado com as notícias sérias do momento. É quase impossível combinar os empregos de tempo integral em funções chaves envolvendo as notícias com a responsabilidade principal por dependentes: "[...] na nossa redação inteira, [as mulheres] que têm filhos e ainda são produtoras de notícias [...] não posso pensar em nenhuma" (repórter sênior, 25, jornal vespertino da cidade). [...] Quando as minhas entrevistadas falavam das suas próprias vidas e perspectivas, ou contavam as dificuldades de colegas mulheres, o tema constantemente recorrente era o horário de trabalho não apenas comprido, mas também anti-social ou imprevisível, ou todas as três coisas - características de um empreendimento implacavelmente motivado pelo lucro estruturado em torno do "dia de notícias" (ALDRIDGE, 2001).

Padrões semelhantes são evidentes nas organizações noticiosas de outros países. Robinson (2005) examina o impacto do "telhado de vidro" no avanço das mulheres nas redações canadenses, onde a legislação estabelecendo a igualdade - que ajuda na obtenção de empregos para as mulheres - não teve o resultado desejado ao se tratar de promoções. McGregor (2006) descreve o que chama o "poder difundido das notícias feitas pelos homens" na mídia noticiosa da Nova Zelândia. Embora as mulheres tenham alcançado pouco progresso em nível de redator, argumenta ela, as coisas estão melhorando para as mulheres seniores logo abaixo daquele nível. Djerf-Pierre (2007) indica que na Suécia, embora as mulheres já constituíssem cinquenta por cento da profissão em 2005, o jornalismo permanece um campo "dominado pelos homens". Sua pesquisa defende que há uma lógica de gênero que configura as definições de status, prestígio e poder, que funciona de maneira a alinhar a masculinidade com "ideias de que constitui bom jornalismo" (DJERF-PIERRE, 2007, p. 99).

Uma pesquisa conduzida pelo Projeto para a Excelência no Jornalismo (PEW) oferece dados quantitativos para apoiar esta linha da crítica. Baseado nos resultados de um exame de uns 16.800 itens de notícias de 45 fontes diferentes, nos Estados Unidos (16 jornais, quatro programas noturnos de notícias, três shows matutinos das redes, nove programas a cabo e nove sites de notícias na Internet) durante 20 dias escolhidos aleatoriamente num período de nove meses em 2004 , os pesquisadores descobriram que os homens são utilizados como fontes de notícias duas vezes mais frequentemente do que as mulheres. "Mais de três quartos de todos os itens de notícias contêm fontes masculinas, enquanto que apenas um terço tem uma só fonte feminina" (PEW, 2005, p. 2). A pesquisa verificou - uma disparidade que foi mantida em todas as diversas mídias pesquisadas. Outros resultados incluíram:

\footnotetext{
* Em cada categoria temática, a maioria dos itens de notícias citou
} 
pelo menos uma fonte masculina.

* Contrastando, a única categoria temática em que as mulheres ultrapassaram a marca de $50 \%$ foi em matérias sobre o estilo de vida.

* A categoria em que a citação de mulheres era menos provável foi a das relações estrangeiras.

* Das mídias pesquisadas, os jornais tinham mais probabilidade de citar pelo menos uma fonte feminina numa matéria $(41 \%$ das matérias). As notícias da TV a cabo, apesar de todo o tempo que elas têm para ocupar, foram a mídia com menos probabilidade de citar uma fonte feminina ( $41 \%$ das matérias), e esta situação se manteve em todos os três canais maiores da TV a cabo.

* Na TV de redes, os programas matutinos de notícias, que muitas vezes tratam de assuntos mais leves, dependiam mais das fontes femininas. Nos programas vespertinos de notícias, isto era algo menos provável, mas mesmo assim dependiam mais das fontes femininas do que os programas da TV a cabo.

* O caderno de esportes do jornal se destacou especialmente como um baluarte masculino. Apenas $14 \%$ das matérias na primeira página do caderno de esportes citaram uma mulher, comparado com $80 \%$ que continham pelo menos uma fonte masculina (PEW, 2005, p. 2-3).

Vista com relação à sociedade norte-americana em geral, onde as mulheres representavam 52 por cento da população (e cerca de 47 por cento da mão de obra civil empregada) na época, esta disparidade é ainda mais reveladora. Aqui os pesquisadores alertam que não há nenhuma sugestão subentendida de que os jornalistas deveriam tentar conseguir um equilíbrio dos gêneros em cada item de notícias. Isto posto, as suas conclusões os levam a sugerir que é preciso tomar medidas para "criar mais oportunidades para que as vozes femininas possam surgir", e com urgência (PEW, 2005, p. 17; ver também os resultados semelhantes de CANN e MOHR, 2001 para as notícias de TV na Austrália; e BECKER e DE BUSTAMANTE, 2009 para o profissionalismo nas notícias de TV no Brasil).

Então, em vista de questões como estas, é evidente que estas normas de reportagem precisam ser contextualizadas com relação aos diferenciais de poder institucionais de longa data dentro do ambiente de trabalho jornalístico (onde tendem a ser defendidos prontamente com referência aos valores de trabalho consistentes com "tradições" e "costumes" masculinizados). A maioria dos jornais parece ser caracterizada por uma divisão em gêneros entre os repórteres das notícias "sérias" (tais como a economia, a política, o governo e o crime), que tendem a serem homens, e os repórteres de "matérias especiais", que mais provavelmente, pelo menos em termos relativos, são mulheres. Esta divisão, longe de correlacionar com as "competências naturais" de repórteres individuais masculinos e femininos ("os homens são mais apropriados para o jogo duro das notícias sérias"), é frequentemente indicativa de uma divisão sexual do trabalho no próprio lar do jornalista. As repórteres femininas 
têm mais probabilidade de vivenciar um "dia dobrado" de trabalho, em que desempenham uma parte desproporcional das responsabilidades domésticas (especialmente cuidar das crianças), do que seus colegas masculinos "mais profissionalmente comprometidos". Fica bem mais fácil administrar estas formas de trabalho relacionadas com os horários mais regularizados, estruturados e previsíveis associados à reportagem de matérias especiais. Daí resulta que "áreas prestigiadas da produção de notícias permanecem em grande parte dominadas pelos homens", escrevem Chambers e Steiner (2010, p. 49), "especialmente na categoria com muito status que é a política, além dos negócios e dos esportes".

Então, por estas razões e por outras razões relacionadas, tornase cada vez mais evidente por que tem sido tão difícil reformular as normas masculinizadas de identidade profissional, apesar dos avanços que as jornalistas estão fazendo mais e mais no que tem sido percebido como um domínio masculino durante tantos anos.

\section{A diversidade étnica e 0 jornalismo}

Nos dias que antecederam a posse do Barack Obama na Presidência dos Estados Unidos, a questão do racismo estava gerando bastante atenção nos comentários da imprensa por motivos óbvios. No entanto, poucas organizações noticiosas estavam enfrentando os seus próprios defeitos com a passagem dos anos, preferindo ao invés disso focalizar exemplos de discriminação racial evidentes em outras instituições sociais. Uma exceção foi o Meridian Star, um jornal do Mississipi, que publicou um pedido de desculpas pela sua reportagem no passado acerca das questões de direitos civis. Num editorial, "Honramos e pedimos desculpas", descreveu os esforços daqueles no Leste do Mississipi que desempenharam um papel integral no movimento que defendia a igualdade. Seus últimos parágrafos diziam:

Houve uma época em este jornal - e muitos outros no sul dos Estados Unidos - atuava com negligência grosseira ao ignorar em grande parte a injustiça da segregação nas escolas, nos ônibus, nos restaurantes, nos banheiros, nos teatros e em outros lugares públicos.

Fizemos isso mediante a omissão, ao deixar de informar aos nossos leitores sobre muitas das mais importantes atividades de direitos civis que aconteceram em volta de nós, inclusive protestos e ocupações de locais. Isso estava errado. Deveríamos ter protestado em voz alta a segregação e os esforços para impedir o registro dos eleitores negros do Leste do Mississipi.

A direção atual do jornal entende que embora não possamos voltar e desfazer alguns erros passados, podemos oferecer nosso pedido sincero de desculpas - e prometer nunca mais negligenciar a nossa responsabilidade de informar a vocês, nossos leitores, sobre os direitos humanos e a dignidade aos quais todo indivíduo na 
América tem direito - não importa sua religião, seus antecedentes étnicos ou a cor de sua pele (MERIDIAN STAR, 2009).

Este pedido de desculpas pela "negligência grosseira" atraiu manchetes por si só, muito possivelmente - espera-se - encorajando outras organizações noticiosas a rever a sua própria cobertura no passado com um olho crítico sobre sua cumplicidade na normalização do preconceito. Se para alguns observadores afro-americanos na blogosfera o pedido de desculpas da Meridian Star foi um caso de "antes tarde do que nunca", para outros representou apenas um primeiro passo que precisava ser seguido rapidamente por ações concretas.

As estatísticas produzidas pela Associação Americana de Redatores de Jornais (ASNE) sublinham a significância deste ponto. Num censo recente da indústria (iniciado como um exercício anual após o relatório da Comissão Kerner de 1968), descobriu-se que a porcentagem de jornalistas das minorias étnicas que trabalhavam nos jornais diários nos Estados Unidos cresceu minimamente em 2007 - especificamente, de 13,43 por cento de todos os jornalistas para 13,52 por cento de 52.600 jornalistas de tempo integral. O Presidente da ASNE, Gilbert Ballon, contextualizou este dado:

Os números representam uma dupla realidade. É um pouco animador que a porcentagem da minoria tenha se mantido estável apesar dos tempos economicamente difíceis que estão causando muitas reduções de despesas. Por outro lado, o número total de jornalistas das minorias, empregados nos jornais diários, declinou por quase 300 pessoas, o que segue o padrão para a mão de obra global nas redações. Tal tendência não vai ajudar aos jornais no seu esforço de alcançar a paridade com a população das minorias até 2025 (ASNE, 2008).

Aqui vale a pena notar que 423 dos jornais que responderam ao levantamento feito pela ASNE registraram que não tinham minorias nos seus quadros de funcionários de tempo integral (a maioria destes jornais tendo tiragens de 10.000 exemplares ou menos). E isto acontece quando "uma redação genérica, monocromática" - usando a frase de Bailon será incapaz de servir adequadamente à sua comunidade de leitores. Na medida em que este problema está sendo ainda mais exacerbado pelas crises financeiras, torna-se mais importante incitar aos gerentes a não abrirem mão do seu compromisso com as melhorias. "A diversidade não é um luxo nem um coqueluche", observa a National Association of Black Journalists (A Associação Nacional de Jornalistas de Cor - NABJ). "É necessário para relatar matérias equilibradas sobre a América e para colocar uma perspectiva nova de matérias perante os leitores através das lentes dos jornalistas das minorias" (NABJ, 2008). 
Embora haja motivos para um otimismo cauteloso de que as coisas estão melhorando, resta muito trabalho a fazer. Um relatório solicitado pela Greater London Authority (Autoridade da Grande Londres - GLA) para pesquisar a cobertura pela mídia impressa britânica dos muçulmanos e do Islã, desde a metade do ano 2006 até a metade do ano 2007, torna este ponto ainda mais evidente. Embora houvesse alguns exemplos da boa prática em evidência (tais como "itens únicos de notícias, matérias especiais, projetos e artigos investigativos"), eles eram considerados exceções à regra geral. Muito mais típicos eram os relatórios noticiosos retratando um antagonismo básico entre o Ocidente e o Islã, com os muçulmanos retratados como "uma ameaça aos costumes, valores e estilos de vida tradicionais britânicos (GLA, 2007, xiii). Distorções, exageros e simplificações excessivas entravam regularmente na cobertura, muitas vezes expressadas em um tom de linguagem que era emotivo, até alarmista. Entre as recomendações para mudanças no relatório encontravam-se as seguintes:

\footnotetext{
* As organizações noticiosas devem rever sua cobertura de questões e eventos envolvendo os muçulmanos e o Islã, e deveriam considerar a elaboração de códigos de conduta profissional e guias de estilo referentes ao uso da terminologia. Tais códigos de conduta profissional deveriam estar baseados na sua própria prática melhor.

* As organizações noticiosas deveriam tomar as providências, talvez dentro do quadro da ação positiva na legislação sobre igualdades, a fim de recrutar mais jornalistas de herança muçulmana que possam refletir com mais precisão os pontos de vista e as experiências das comunidades muçulmanas.

* As organizações noticiosas deveriam também considerar a melhor maneira de dar um apoio profissional apropriado aos funcionários muçulmanos e impedir que estes sejam restritos apenas como especialistas em questões das minorias ao invés de participarem no espectro inteiro da produção de uma organização. * As organizações noticiosas deveriam tratar seriamente as queixas relacionadas com a cobertura distorcida do Islã e dos muçulmanos na mídia (GLA, 2007: xiv-xv).
}

$\mathrm{Na}$ sustentação de cada uma destas recomendações está o reconhecimento compartilhado de que o preconceito antimuçulmano precisa ser reconhecido e tratado como uma forma de discriminação. Seus efeitos prejudiciais se encontram em ambas as direções, ou seja, a reportagem preconceituosa provavelmente "produz, provoca e aumenta os sentimentos de insegurança, suspeita e ansiedade entre os não-muçulmanos", enquanto que ao mesmo tempo, provavelmente, "provoca sentimentos de insegurança, vulnerabilidade e alienação entre os muçulmanos" (CLA, 2007; ver também BAILEY, 2007; MELLOR, 2005; POOLE e RICHARDSON, 2006). 
Laura Smith (2007), uma jornalista do Guardian e uma das pesquisadoras para o relatório (junto com o seu colega Hugh Muir), descobriu no curso de sua pesquisa, que os padrões jornalísticos básicos eram rotineiramente comprometidos onde às matérias noticiosas pudessem ser dadas um "ponto de vista muçulmano". Com relação às dificuldades de realizar uma mudança, no entanto, ela oferece a seguinte percepção:

\footnotetext{
Os jornalistas, incluindo eu mesma, sempre ficam um pouco aborrecidos quando são criticados. Após ter trabalhado para jornais onde eu poderia não ter concordado com a sua linha editorial, conheço as pressões as quais os jornalistas podem ser submetidos para fazer uma matéria funcionar, independentemente dos fatos. Mas nós como profissionais precisamos arcar com mais responsabilidade pelas matérias que colocamos no domínio público e pelo efeito elas causam na sociedade mais ampla. Verdadeiras ou não, estas matérias mergulham profundamente na consciência pública e não podem deixar de influenciar a maneira com que as pessoas percebem umas às outras. Quando, como no caso de matérias envolvendo muçulmanos, e antes deles as pessoas de cor e pessoas judaicas, estas matérias não são compensadas por uma cobertura mais equilibrada, os resultados podem fazer danos profundos (SMITH, 2007).
}

A jornalista Angela Phillips (2007), ao comentar os resultados do relatório bem como a sua própria pesquisa relacionada a ele, indica que "os jornalistas na imprensa inteira, sejam de jornais liberais ou mais conservadores, têm muito a pensar sobre as questões de representação." Novas maneiras têm que ser encontradas para ir além do discurso da "tolerância" tipicamente expressado pelos jornais, a fim de realmente parar de representar os muçulmanos como "visitantes" no "nosso" país, e assim reconhecer devidamente todo mundo como concidadãos com direitos iguais.

Um exemplo da forma que tal ação pode assumir é descrito por Harker (2010) a respeito das mudanças em curso em alguns jornais britânicos. O progresso na melhoria do número de repórteres de minorias étnicas empregados tem sido lento, ele afirma, porém está melhorando gradualmente devido a um número de estratégias. Ele descreve uma iniciativa em curso no jornal The Guardian, em Londres, onde um programa de recrutamento com ação positiva - com a pretensão de atrair as minorias raciais - está funcionando. "O grande número de homens e mulheres jovens, inteligentes, entusiasmados, bons trabalhadores e motivados que conseguimos trazer para o nosso escritório (e, sim, mulheres muçulmanas também)", ele observa, "tem desmentido aquele velho mantra, 'mas eles não solicitam emprego'” (HARKER, 2010, p. 313). Outros aspectos do plano de ação para corrigir a desigualdade incluem 
"entrevista, recrutamento e treinamento gerencial para os redatores e os chefes de seção, consultas com os funcionários de minorias, anúncios externos de todos os empregos de nível de entrada na empresa, e alertas aos jornalistas de minorias na nossa base de dados quando surgem vagas" (Ibid, p. 313). Uma dimensão crucial para estes esforços, ele pensa, é o monitoramento étnico a fim de medir o progresso relativo. Este compromisso desafia o ponto de vista mais típico expressado pelos redatores, a saber, que a etnia é irrelevante numa redação que funciona na base do desempenho. Em resposta, Harker pergunta:

\begin{abstract}
Sem quaisquer informações de apoio, os jornais realmente podem ter a certeza de que seu recrutamento não tem preconceito e que seus redatores olham além dos fatores culturais indeterminados que tão frequentemente ficam atrás das decisões de seleção, tais como: "Me sinto confortável com ele?" "Ela seria o objeto de muito riso lá no bar?" "Eles se encaixariam bem com a nossa equipe de reportagem?" Os jornalistas contatados por mim que trabalham em algumas destas redações relataram que são lugares muito brancos mesmo (HARKER, 2010, p. 314).
\end{abstract}

Daí segue que o enriquecimento da diversidade da "cultura interna" de uma organização noticiosa é de importância vital, e está muito atrasado. "Pode-se encontrar ocasionalmente um jornalista de cor ou asiático num papel júnior na mesa de encomendas, mas raramente, se houver, numa posição em que possa tomar uma decisão sobre o que vai entrar no jornal do dia seguinte, e muito menos ter qualquer impacto a longo prazo" (Ibid, s.p.), ele acrescenta. O tratamento justo dos empregados dentro da organização certamente vai resultar em melhorias na qualidade da reportagem (uma outra dimensão que exige um monitoramento de perto), o que vai trazer bastante benefícios sociais para todo mundo.

Numa época em que tantas organizações noticiosas estão lutando para sobreviver à crise financeira global, cresce o medo de que alguns sejam obrigados a abandonar seus compromissos com a diversidade. Nos Estados Unidos, o redator Mark Fitzgerald acha que há um "sentimento difundido de que a economia empurrou as metas de diversidade não somente para trás, mas totalmente para fora" (EDITOR \& PUBLISHER, 2008). Este recuo está sendo sentido nas redações, e também o fato dos jornais não terem aproveitado este momento como uma oportunidade de olhar além dos conceitos tradicionais (branco, masculino) dos consumidores das notícias para atrair uma audiência muito mais ampla na comunidade. "Se não pensarmos nestas audiências diversas agora, e trabalharmos duro para consegui-las, poderemos estar correndo o risco de perdê-las para sempre", defende a redatora 
executiva Wanda Lloyd, antes de acrescentar que "a diversidade no quadro de funcionários e no conteúdo vão de mãos dadas. Se você tem um compromisso com um deles, provavelmente tem compromisso com os dois" (apud ANDERSON, 2008).

\section{Os Jornalistas de amanhã}

Em vista desta exploração, então, poderíamos reconhecer, na medida em que a pesquisa crítica está conseguindo documentar, o hiato entre a retórica da identidade jornalística e sua materialidade vivida nos contextos cotidianos. A intervenção de Pulitzer, mencionada no início deste artigo, se referiu à melhoria da relevância da identidade jornalística para os valores democráticos, com o propósito de assegurar que na preparação dos jornalistas, cidadãos fossem produzidos. Como tal, aquela intervenção continua até os dias de hoje representando uma chamada para a mudança tanto nas redações quanto nas salas de aula do Jornalismo.

Daí segue que uma maneira de lidar com as formas de preconceito analisadas aqui é revigorar a identidade do jornalista como cidadão. "A escola moderna do jornalismo começa o seu ensino com as premissas da profissão que ela serve", observou Carey (1978, p. 853) há umas três décadas: "Ao transmitir a linguagem do profissionalismo disponibiliza para os alunos um "mundo dado por certo" do jornalismo que é raramente questionado ou analisado criticamente". Ao considerar que, na medida em que isto continua sendo verdadeiro atualmente, quando as abordagens estabelecidas há muitos anos para a educação jornalística correm o risco de aparecer anacrônicas neste bravo mundo novo da Internet, convida para um grau bem-vindo de auto-reflexão sobre todos os aspectos da provisão de um programa universitário (ver também FRANCISCATO, 2010; MOREIRA e HELAL, 2009). As pressões sobre os educadores de jornalismo para fazer com que seu currículo esteja de acordo com as exigências variáveis da indústria das notícias têm que ser enfrentadas em níveis diferentes, porém especialmente com relação às implicações para o ensino daquilo que vale como uma identidade apropriada - em termos tanto pessoais quanto coletivos - para o jornalista de amanhã. Quando as abordagens pedagógicas conhecidas ameaçam desemaranhar, é vital que um compromisso renovado com a experiência e a exploração seja mantido.

O papel prestigioso certa vez tido como a exclusiva origem do jornalista profissional está sendo rapidamente reescrito no atual panorama da mídia, um processo que é de tão longo alcance nas suas implicações quanto inevitável. Qualquer sentido de complacência, especialmente 
quando enraizado nas normas e nos valores da reportagem de notícias, deve ser reformulado antes que alternativas viáveis comecem a encontrar seu ponto de apoio. Para os jornalistas dispostos a participar do diálogo e debate sobre como definir melhor a sua identidade em novas e progressivas maneiras, poderá se mostrar vantajoso começar não com as premissas de uma profissão que procuram servir, mas com as suas obrigações com os públicos diversos cujos interesses afirmam representar.

\section{BIBLIOGRAFIA}

ALDRIDGE, M. The Paradigm Contingent Career? Women in Regional Newspaper Journalism. Sociological Research Online, vol. 6, no. 3, 2001.

ALLAN, S. News Culture, Third Edition. Maidenhead and New York: Open University Press, 2010a.

Professionalism: Journalism Without Professional Journalists? In STEINER, L. And CHRISTIANS, C. (Eds). Key Concepts in Critical Cultural Studies. Urbana: University of Illinois Press, 2010b. p. 145-157.

ASNE - American Society of Newspaper Editors. Newsroom Employment Census, 2008. Disponível em <www.asne.org/index.cfm?id=1138>.

ANDERSON, M.D. Minority Journalists Push Media to Maintain Diversity Commitment. Issues in Higher Education, 24 July, 2008.

BAILEY, O.G. (Ed). Transnational Lives and Media: Re-imagining Diasporas. London: Palgrave, 2007

BECKER, B. and DE BUSTAMANTE, C.G. The past and the future of Brazilian television news. Journalism, Vol. 10(1): 45-68, 2009.

BOYLAN, J. Pulitzer's School. Columbia University's School of Journalism, 1903-2003. New York: Columbia University Press, 2003.

CANN, D.J. and MOHR, P.B. Journalist and Source Gender in Australian Television News. Journal of Broadcasting \& Electronic Media, 45(1): 162-174, 2001.

CAREY, J.W. A Plea for the University Tradition. Journalism Quarterly, Volume 55, Winter, 846-855, 1978.

CARTER, C., BRANSTON, G. and ALLAN, S. (Eds). News, Gender and Power. London and New York: Routledge, 1998.

CHAMBERS, D. and STEINER, L. The Changing Status of Women Journalists. In S. Allan (Ed). The Routledge Companion to News and Journalism. London and New York: Routledge, 2010.

CHAMBERS, D., STEINER, L. and FLEMING, C. Women and Journalism. London and New York: Routledge, 2004.

Christmas, L. Chaps of Both Sexes? Women Decision-Makers in 
Newspapers: Do They Make a Difference? Wiltshire: Women in Journalism in association with The BT Forum, 1997.

COOPER, G. The hell of being white, middle-class and male. The Telegraph, 22 December, 2008.

COURIC, K. A woman at the table. CBS Blogs, Couricand Co. 17 January, 2007.

DE ALBUQUERQUE, J.A. Another "Fourth Branch": Press and political culture in Brazil. Journalism, Vol. 6(4): 486-504, 2005.

DE BRUIN, M. and ROSS, K. Gender and Newsroom Cultures. Crestkill, NJ: Hampton Press, 2004.

DJERF-PIERRE, M.The Gender of Journalism. Nordicom Review, 81-104, 2007.

EDITOR \& PUBLISHER, s.l./USA, July, 25, 2008.

EVERBACH, T. The culture of a women-led newspaper. Journalism and Mass Communication Quarterly, 83(3): 477-493, 2006.

FRANCISCATO, C.E. Tendencies in the development and consolidation of journalism research in Brazil. Communicatio: South African Journal for Communication Theory and Research, Vol. 36(2):172 - 184, 2010.

GLA - Greater London Authority. The search for common ground: Muslims, non-Muslims and the UK media. 2007. Disponível em <www. london.gov.uk>.

HARKER, J. Race and Diversity in the News. In ALLAN, S (Ed). The Routledge Companion to News and Journalism. London and New York: Routledge, 2010.

HERSCOVITZ, H. G. Brazilian journalists' perceptions of media roles, ethics and foreign influences on Brazilian journalism. Journalism Studies, 5: 1, 71-86, 2004. Disponível em <http://www.suttontrust.com/reports/ Journalists-backgrounds-final-report.pdf>

IRELAND, A. An Adventure with a Genius: Recollections of Joseph Pulitzer. London: Lovat Dickson, 1938.

MARQUES DE MELO, J. Journalistic thinking : Brazil's modern tradition. Journalism, Vol. 10(1): 9-27, 2009.

MARTINEZ, M. The Good Listeners: Joseph Mitchell (U.S.), José Hamilton Ribeiro (Brazil) and Literary Journalism. Brazilian Journalism Research, Vol. 4(1): 121-139, 2008.

MCGREGOR, J. The Pervasive Power of Man-made News. Pacific Journalism Review, 12(1): 21-34, 2006.

MELLOR, N. The Making of Arab News. Lanham, MD: Rowman \& Littlefield, 2005.

MERIDIAN STAR. Editorial: We honor and we apologize. Mississipi/USA, Meridien Star, jan. 18, 2009.

MOREIRA, S.V. and HELAL, C.L.R. Notes on media, journalism education 
and news organizations in Brazil. Journalism, Vol. 10(1): 91-107, 2009. NABJ - National Association of Black Journalists. Newspaper Industry Should Not Treat Diversity like a Passing Fad. Press Release, 2008. . Disponível em <www.nabj.org $>$.

NORTH, L. The Gendered Newsroom: How Journalists Experience the Changing World of Media, Creskill, NJ: Hampton, 2009.

PHILLIPS, A. Muslims and the media. The Guardian, 15 November, 2007.

POOLE, E. \& RICHARDSON, J. E. (Eds). Muslims and the News Media. London: IB Tauris, 2006.

Project for Excellence in Journalism. The gender gap: women are still missing as sources for journalists. 23 May 2005. Disponível em < www. journalism.org/files/gender.pdf>.

PULITZER, J. The School of Journalism in Columbia University, 2006 facsimile reproduction. The School of Journalism. Seattle: Inkling Books, 1904.

SEITZ, D.C. Joseph Pulitzer: His Life \& Letters. New York: Simon \& Schuster, 1924.

SMITH, L.You couldn't make it up. The Guardian, 15 November, 2007.

SUTTON TRUST. The Educational Backgrounds of Leading Journalists, June, 2006.

WALKER, T. Paxo must be undergoing a mid-life crisis. The Telegraph, 26 August, 2008.

WOMEN IN JOURNALISM. The Cheaper Sex: How Women Lose Out in Journalism. London: WIJ Secretariat, 1998.

Stuart Allan é professor de jornalismo na Escola de Mídia na Universidade de Bournemouth, no Reino Unido. Seus livros escritos recentemente incluem Digital War Reporting (em parceria com D. Matheson, 2009), Nanotechnology, Risk and Communication (em parceria com A. Anderson, A. Petersen e C. Wilkinson, 2009), News Culture (3 ed., 2010) e Keywords in News and Journalism Studies (em parceria com B. Zelizer, 2010). Suas coletâneas publicadas incluem Citizen Journalism: Global Perspectives (em parceria com E. Thorsen, 2009), Rethinking Communication (2010) e The Routledge Companion to News and Journalism (2010). 